\title{
Influence of Bulk-fill, Flowable, and Dual-cure Resin Restorative Materials on Intrapulpal Thermal Changes during Polymerization with Light-curing Units at Curing Tip Distance
}

\author{
Killi N Kumar ${ }^{1}$, Vanga Narsimha Rao V ${ }^{2}$, Chandrabhatla S Kumar ${ }^{3}$
}

\begin{abstract}
Aim and objective: The purpose of the study was to evaluate the temperature changes in the pulp chamber that occur during the polymerization of bulk-fill, flowable bulk-fill, and dual-cure resin restorative materials influenced by various light-curing devices at different curing tip distances. Materials and methods: In the present in vitro study, dentin discs of $1 \mathrm{~mm}$ thick and Teflon molds with a cylindrical cavity of $2 \mathrm{~mm}$ diameter with lengths of 3,4 , and $5 \mathrm{~mm}$ were used to simulate tooth structure with a prepared occlusal cavity. Teflon molds were restored with $2 \mathrm{~mm}$ Spectrum (universal microhybrid composite Dentsply), Tetric $\mathrm{N}$ flow (Bulk Fill Ivoclar-Vivadent), and Cention $\mathrm{N}$ (self-curing resin based with light-curing option Ivoclar-Vivadent), respectively, the remaining difference in the length of the Teflon mold depicts the curing tip distance for the light-curing units. Process of photopolymerization was done with LEDition Ivoclar-Vivadent and $3 \mathrm{M}^{\mathrm{TM}} \mathrm{ESPE}^{\mathrm{TM}}$ Elipar $^{\mathrm{TM}} 2500 \mathrm{halogen}^{\mathrm{Curing}}$ unit at curing tip distances of 1, 2, and $3 \mathrm{~mm}$, respectively. The thermal changes below the dentin discs were recorded on the K-type digital thermocouple (DT-302-1 HTC). These values obtained were tabulated and submitted to statistical analysis using analysis of variance (ANOVA) and Tukey's multiple post hoc procedures.

Results: Significant differences were observed in the temperature rise among bulk-fill, flowable bulk-fill, and dual-cure resin ( $p<0.05)$. Halogen curing unit exhibited significantly higher temperature rise than LEDition $(p<0.05)$. The smallest rise in temperature was observed in Spectrum composite with LEDition.

Conclusion: The polymerization process and the amount of temperature rise are important in pulpal health. Even though there was a significant rise in temperature of the pulp, it had no significance in causing irreversible changes to the underlying tooth structures, which is attributed to improved properties of the materials.

Keywords: Cention N, Spectrum, Tetric N flow.

International Journal of Experimental Dental Science (2020): 10.5005/jp-journals-10029-1212
\end{abstract}

\section{INTRODUCTION}

The development of new curing resin materials to meet the increased demand for esthetic dentistry had revolutionized dental restorations. This lead to the introduction of various types of resin materials that possess favorable optical, mechanical properties, and good bonding properties. ${ }^{1}$ They consist of organic matrix and inorganic filler portion consisting of either boron silicates, silicon dioxide, and lithium aluminum silicates. Partial replacement of Quartz by radio-opaque materials such as barium, zinc, strontium, zirconium, or aluminum, ceramic or silica determine both physical and mechanical properties of the resin materials. ${ }^{2,3}$ The process of polymerization of these resin restorative materials is done either with light-curing units (LCUs) or with both chemical and LCUs.

Among the curing light devices, the most commonly used are the light-emitting diode (LED) and Quartz Tungsten Halogen (QTH) curing devices. The emission of the required wavelength of 400-500 $\mathrm{nm}$ (blue light) was controlled by a selective group of filters. At this wavelength, the curing units activate camphorquinoneamine photoinitiation systems present in the resins. Only a fraction of the light source was used for polymerization and photoinitiation; the remaining energy was transformed into heat. ${ }^{1,3,4}$ After the activation of the photoinitiator molecules, the free radicals were generated to initiate the polymerization process. ${ }^{5}$

Regardless of the type of curing unit, the energy transmitted from the curing device, the process of polymerization by
${ }^{1-3}$ Department of Paedodontics and Preventive Dentistry, GITAM Dental College and Hospital, Visakhapatnam, Andhra Pradesh, India

Corresponding Author: Killi N Kumar, Department of Paedodontics and Preventive Dentistry, GITAM Dental College and Hospital, Visakhapatnam, Andhra Pradesh, India, Phone: +91 8309777606, e-mail: nidesh08@gmail.com

How to cite this article: Kumar KN, Narsimha Rao VV, Kumar CS. Influence of Bulk-fill, Flowable, and Dual-cure Resin Restorative Materials on Intrapulpal Thermal Changes during Polymerization with Light-curing Units at Curing Tip Distance. Int J Experiment Dent Sci 2020;9(2):56-61.

Source of support: Nil

Conflict of interest: None

light-activated resin composite, degree of conversion, depth of cure, curing time results in an increase of the temperature in the material and underlying dentin surface by both exothermic polymerization reaction and by the absorption of light energy during the irradiance. ${ }^{6,7}$

The heat transfer in the tooth is based on the conduction and convention process of the dentin. ${ }^{7}$ In case of cold or compressed air stimuli, the fluid seems to have outward flow from the capillarylike tubules, and in case of heat and chewing pressure on a loose filling, movement of tubular fluid seems to flow inward that is in the direction of pulp is observed. The mechanism of inward or 
outward movement of tubular fluid leads to the direct mechanism of deformation. ${ }^{8}$

These abrupt changes in the temperature between the teeth and restorative interface by any process of activation may cause vulnerable effects on the pulp tissue. A small rise in intrapulpal temperature-induced lead to histological evidence of pulpitis of differing severity irrespective of the method of heat stimuli. ${ }^{7}$ Considering all the features of the pulp-composites, flowable composites, and dual-cured resin cement, and LED and QTH curing light devices in the present study focuses on evaluating their influence on the temperature variations in the tooth pulp chamber.

\section{Materials and Methods}

Human permanent molar teeth without any decay or restorations extracted for orthodontic purposes and periodontal reasons were stored in a saline solution to prevent dehydration. They are mounted in a plaster model till the cementoenamel junction leaving the clinical crown exposed for sectioning.

Using a long-tapered TR-13 bur and a slow speed diamond cutting disc (C01/220), approximately $1 \mathrm{~mm}$ size dentin discs (Fig. 1) were prepared under constant water cooling, and their final thickness was measured with a digital Vernier caliper.

Teflon molds of different lengths (3, 4, and $5 \mathrm{~mm}$ ) (Fig. 2) and internal cylindrical cavity of a diameter of $2 \mathrm{~mm}$ were taken and into this cylindrical cavity restorative materials were inserted and photopolymerized in accordance with the manufacturer's guidelines. An acrylic mold was prepared to support the dentin disc and Teflon mold with an access in the center for the passage of thermocouple guide tip to contact the dentin discs on its lower surface to measure the internal rise of the temperature of the specimen.

The curing devices used were LEDition, Ivoclar Vivadent $(430-490 \mathrm{~nm}), 10 \mathrm{~mm}$ tip diameter, and $3 \mathrm{M}^{\mathrm{TM}}$ ESPE $^{\mathrm{TM}}$ Elipar $^{\mathrm{TM}} 2500$ Halogen curing unit (400-500 nm), $8 \mathrm{~mm}$ tip diameter. Three commercially available resin materials used were SpectrumUniversal microhybrid composite restorative (Dentsply), Tetric N flow Bulk Fill (Ivoclar-Vivadent) flowable composite, and Cention $\mathrm{N}$ (Ivoclar-Vivadent) dual-cured resin cement to represent the variation in the range of inherent exothermic reaction occurred during polymerization for the quantification of thermal changes produced from the curing devices.

A total of 90 samples of dentin discs were taken and divided into three groups of 15 based on the light-curing device used. Each sample based on the type of restorative material placed was again subdivided into 5 samples based on the curing light tip distance to the restorative material, which was standardized to $(1,2$, and $3 \mathrm{~mm})$.

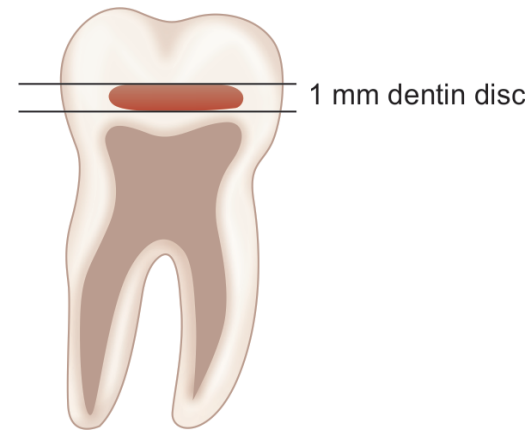

Fig. 1: $1 \mathrm{~mm}$ size dentin discs
Over the dentin discs the Teflon molds were placed and a uniform length of $2 \mathrm{~mm}$ thick incremental layer of the restorative materials were placed in the internal cylindrical cavity of Teflon molds with a cylindrical condenser and the length of the material placed was measured with Williams probe and polymerized without using a bonding agent. The remaining difference in the length of the Teflon mold and the restorative material determines the curing light tip distance to the material.

Then, the entire apparatus was placed in the thermally regulated water bath to maintain $\left(37 \pm 0.5^{\circ} \mathrm{C}\right)$ which simulate oral cavity temperature. The acrylic stand was repositioned above the water bath such that it was immersed to a height with the crosssection of dentin discs and Teflon mold parallel to the water surface and exposed to the external environment.

Then, the restorative materials were irradiated for 40 seconds with a curing-light tip (Fig. 3) in contact with the Teflon molds, to standardize the distance of the light source and material. The initial reading of the dentin discs was recorded, and the highest temperature change noted during the process of curing, was recorded, which is shown on the digital screen of the thermocouple.

\section{Results}

The results obtained were tabulated and submitted to statistical analysis using analysis of variance (ANOVA) and Tukey's multiple post hoc procedures.

Table 1 represents that Spectrum recorded the lowest mean temperature value $\left(1.00 \pm 0.27^{\circ} \mathrm{C}\right)$ at $2 \mathrm{~mm}$ distance from the tip of LED curing device and Tetric $\mathrm{N}$ flow recorded the lowest mean temperature values $1.26 \pm 0.17$ and $0.66 \pm 0.05^{\circ} \mathrm{C}$, respectively, at 1 and $3 \mathrm{~mm}$ distance from the tip of LED curing device.

Table 2 depicts Spectrum recorded the highest mean temperature value of $1.60 \pm 0.34^{\circ} \mathrm{C}$ when the QTH device tip was positioned at $3 \mathrm{~mm}$. The lowest mean temperature value $2.12 \pm$ $0.89^{\circ} \mathrm{C}$ was recorded with Spectrum at a $1 \mathrm{~mm}$ distance from the tip of the QTH curing device. The Cention N recorded the lowest mean temperature values $1.38 \pm 0.08$ and $0.72 \pm 0.33^{\circ} \mathrm{C}$, respectively, at 2 and $3 \mathrm{~mm}$ distance from the tip of the QTH curing device.

Tables 3 and 4 represent the mean temperature change of different composite materials at various periods in seconds during polymerization with LED and QTH lights, respectively. The maximum rise in temperature value was seen within the first 20 seconds of the curing process in all three different positions of the curing light tip. A gradual decrease in the temperature values was observed when the curing tip distance increased from 1 to $3 \mathrm{~mm}$ and from the initial point of material placement to 40 seconds of the final curing process.

\section{Discussion}

In dentistry, the same basic monomer family was used as an entire gamut for resin-based restorative products and methacrylates and vinyl, free radical addition polymerization. ${ }^{1}$ Originally use of
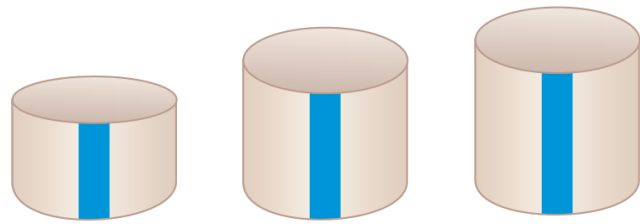

$3 \mathrm{~mm}, 4 \mathrm{~mm}$ and $5 \mathrm{~mm}$ teflon moulds

Fig. 2: Teflon molds of different lengths $(3,4$, and $5 \mathrm{~mm})$ 


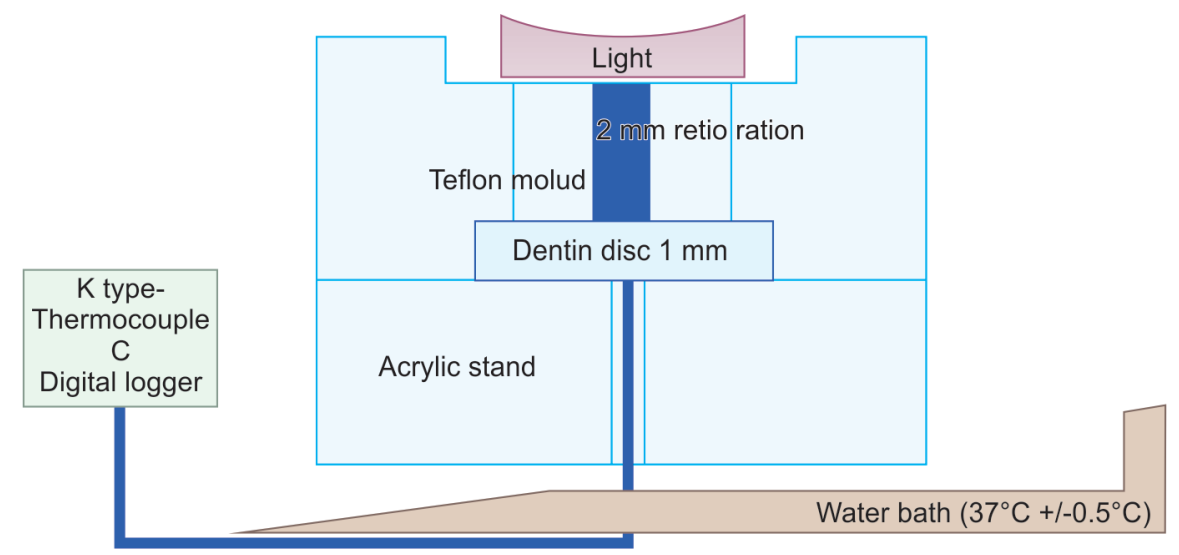

Thermocouple wire

Fig. 3: Complete apparatus

Table 1: Comparison of mean dentinal temperature changes in Celsius $\left({ }^{\circ} \mathrm{C}\right)$ produced by an LED curing device in different materials at different distances

\begin{tabular}{|c|c|c|c|c|c|c|c|c|}
\hline \multirow[b]{2}{*}{ Materials } & \multicolumn{2}{|c|}{$1 \mathrm{~mm}$} & \multicolumn{2}{|c|}{$2 \mathrm{~mm}$} & \multicolumn{2}{|c|}{$3 \mathrm{~mm}$} & \multirow[b]{2}{*}{ Fvalue } & \multirow[b]{2}{*}{$p$ value } \\
\hline & Mean & $S D$ & Mean & $S D$ & Mean & $S D$ & & \\
\hline Spectrum & 1.28 & 0.08 & 1.00 & 0.27 & 0.68 & 0.18 & 11.8596 & $0.0014^{*}$ \\
\hline Tetric N flow & 1.26 & 0.17 & 1.08 & 0.11 & 0.66 & 0.05 & 33.0698 & $0.0001^{*}$ \\
\hline Cention N & 1.32 & 0.16 & 1.26 & 0.36 & 0.88 & 0.13 & 4.9651 & $0.0268^{*}$ \\
\hline
\end{tabular}

*Denotes significance $(p<0.05)$

Table 2: Comparison of mean dentinal temperature changes in Celsius $\left({ }^{\circ} \mathrm{C}\right)$ produced by QTH curing device in different materials at different distances

\begin{tabular}{|c|c|c|c|c|c|c|c|c|}
\hline \multirow[b]{2}{*}{ Materials } & \multicolumn{2}{|c|}{$1 \mathrm{~mm}$} & \multicolumn{2}{|c|}{$2 \mathrm{~mm}$} & \multicolumn{2}{|c|}{$3 \mathrm{~mm}$} & \multirow[b]{2}{*}{ Fvalue } & \multirow[b]{2}{*}{$p$ value } \\
\hline & Mean & $S D$ & Mean & $S D$ & Mean & $S D$ & & \\
\hline Spectrum & 2.12 & 0.89 & 1.82 & 0.40 & 1.60 & 0.34 & 0.9560 & 0.4118 \\
\hline Tetric N flow & 2.20 & 0.22 & 1.94 & 0.44 & 1.34 & 0.35 & 7.9727 & $0.0063^{*}$ \\
\hline Cention N & 2.36 & 0.17 & 1.38 & 0.08 & 0.72 & 0.33 & 69.4830 & $0.0001^{*}$ \\
\hline
\end{tabular}

*Denotes significance $(p<0.05)$

ultraviolet (UV) light at a wavelength around $365 \mathrm{~nm}$ was used to cause polymer curing. Despite using this system for many years, lack in incremental thickness placement $>1 \mathrm{~mm}$, exposure for each increment for 20-60 seconds led to the development of a visible light curing system which involves the wavelength of the visible light to interact (absorption) of photons converted into energy used for the creation of free radicals leading to polymerization. ${ }^{2-4}$

Many visible light-curing devices are available like Quartztungsten-halogen lights Argon-ion lasers (QTH), Plasma-arc lights (PAC), Argon-ion lasers, and Light-emitting diodes. Among these QTH and LED are the most frequently used devices in dentistry, they were taken in the present study. ${ }^{3}$

Composite material polymerization occurs when the light emitted from the curing device comes in contact with them. The wavelength of this light source is significant in the quality of polymerization. ${ }^{9}$ In addition to the wavelength, the curing device's distance to the restorative material, exposure time also influences the extent of the polymerization process. ${ }^{10}$ But it has been found that during this process degree of conversion, shrinkage strain, and polymerization rate of the material also influence a rise of temperature. ${ }^{11}$

The rise in temperature during polymerization will stimulate the pulpal nervous system, which in turn alters the blood level in the pulp microcirculation. ${ }^{12}$ Histological studies conducted by Zach and Cohen ${ }^{13}$ showed that temperature rise in $5.6^{\circ} \mathrm{C}$ might cause $15 \%$ loss of the vitality in the pulp, and a temperature rise of about $11^{\circ} \mathrm{C}$ causes $60 \%$, and $16.6^{\circ} \mathrm{C}$ rise causes $100 \%$ necrosis of the pulp. ${ }^{14}$ The pulp microcirculation and blood flow had no notable changes between temperatures ranging from 31 to $43^{\circ} \mathrm{C}$. But when the temperature drops below $31^{\circ} \mathrm{C}$, a notable drop of pulpal blood flow was seen, and at temperatures above $43^{\circ} \mathrm{C}$, a pronounced increase in blood flow was noted which was associated with a rapid and irreversible breakdown of pulp microcirculation. ${ }^{15}$ The temperature rise will also alter the fluid motion in the dentinal tubules leading to protoplasmic coagulation, structural changes in blood vessels, causing tissue necrosis of the pulp. ${ }^{14}$

The disperse phase of resin materials was incorporated with inorganic filler particles of silicon dioxide, boron silicates, and lithium aluminum silicates which vary widely in their chemical composition, morphology, and dimensions. ${ }^{16}$ In addition to filler particles to the organic matrix phase enhances both physical and mechanical properties, thermal expansion coefficient, and overall curing shrinkage of the material. The amount of residual monomer, free radicals, and the pigments present in the resin matrix also affect the rate of polymerization and heat of the reaction of the material. Thus, the differences in the composition of various components lead to the alteration in the outcome of the materials. ${ }^{16,17}$

Considering these factors, three materials with different properties, Spectrum composite (Dentsply), Tetric $\mathrm{N}$ flow bulk-fill 

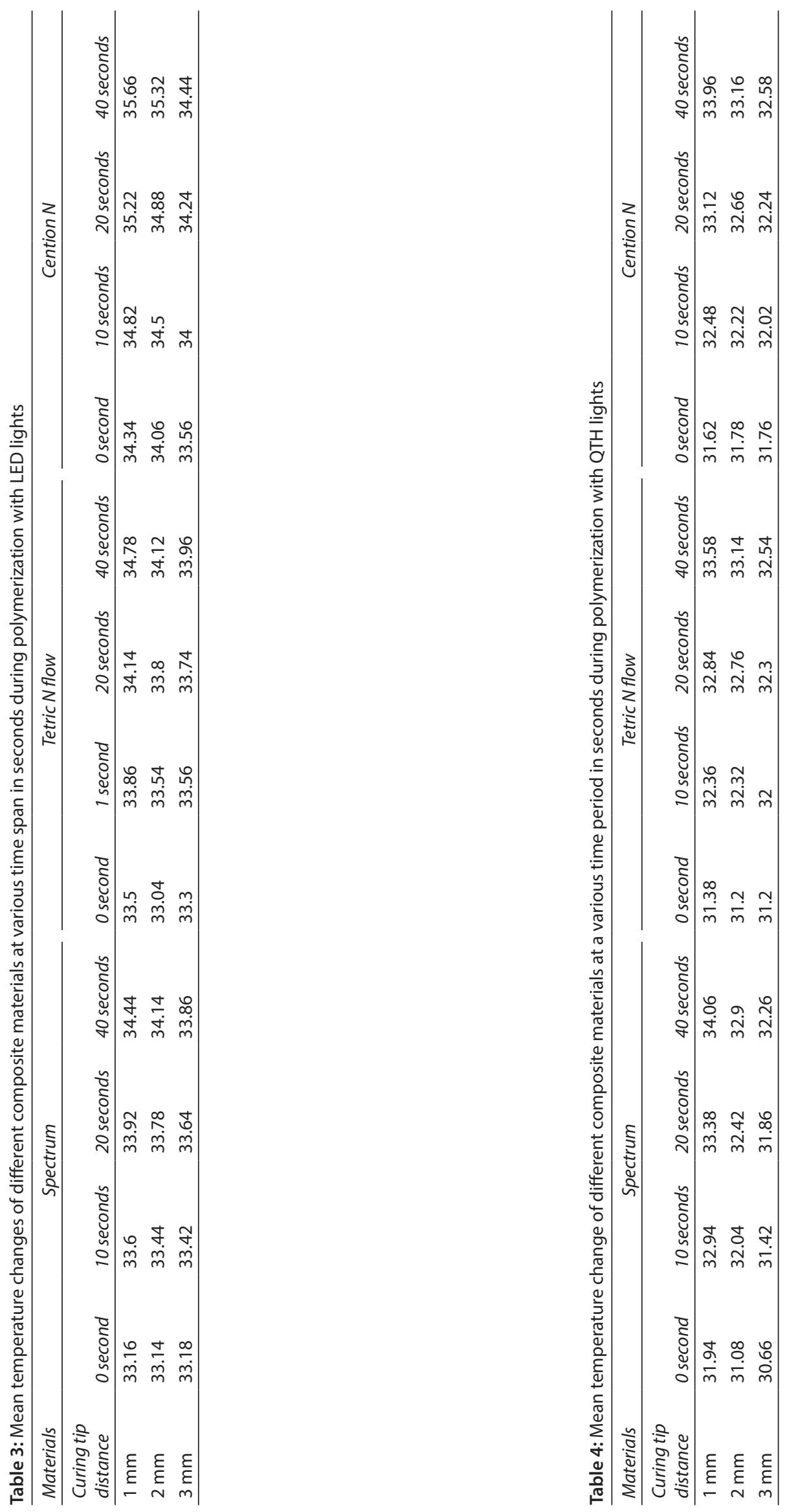
flowable composite (Ivoclar Vivadent), and Cention N (Ivoclar Vivadent) were chosen for the study.

Of the tests conducted in the 90 samples, all three resin materials exhibited exothermic behavior. Dual-cured Cention N showed the maximum mean rise in temperature when polymerized with QTH and LED curing lights followed by Tetric N flow bulkfill flowable composite and Spectrum composite. The results of the study were explained by the previous studies conducted by Oliveira et al. ${ }^{18}$

Cention $\mathrm{N}$ being the bottle system, on mixing the powder and liquid, the acid-base reaction starts followed by a free radical polymerization reaction, generated by photoinitiators and chemical mediators during the curing process by LCUs. They exhibit a rapid phase of curing and a higher degree of conversion resulting in a high degree rise of temperature. The other factors involved were the darker shade A2 tooth shade of the material, and its radio-opaque nature increased filler content which plays a key role in influencing the variation in temperature during the process of polymerization while curing with curing devices. ${ }^{19-21}$

When polymerization was done at a longer distance $3 \mathrm{~mm}$ curing light tip distance, the highest rise in temperature was seen with the Spectrum material, as it has more resin matrix and filler content. The polymerization process related to the filler and monomer type, the content of the polymer matrix, refractive index mainly impact the ability of the light to get transmitted throughout the composites. As a result, even though there was an increase in the curing light tip distance from the material the depth of cure was adequate than the flowable composites and dual-cured materials which might have resulted in an adequate degree of conversion leading to more rise in temperature below the dentin structure. ${ }^{22,23}$

The difference in the thermal behavior of the Spectrum composite might be associated with the presence of monomeric resin matrix of Bis-GMA-adduct, TEGDMA with highly dispersed silicon dioxide with barium aluminum borosilicate particles. ${ }^{24}$ Experimental observations shown that thermal insulating properties of silorane-based composite resins were less in comparison to methacrylate-based composite resins resulting in a greater rise in temperature. ${ }^{25}$

The temperature changes below restorations when polymerized with quartz-tungsten halogen (QTH) and LED curing the maximum increase in temperature was found with QTH curing unit as it was speculated that light emitted by a halogen curing light was by an incandescent filament which transmits more heat than the other curing device. ${ }^{26}$

There was a gradual increase in temperature when the irradiance time from the point of curing was increased to the time point of 40 seconds at all the curing tip positions. The phases that were present during the time of curing were the cooling phase between the peak temperature, and end of the curing cycle and the later was rapid cooling phase at the end of the curing cycle and the end of temperature monitoring. There was a steady decrease in temperature from the initial temperature peak to the end of light curing. The maximum rise in temperature was seen in the first 20 seconds, and the least was seen in the next 20 seconds. ${ }^{27}$

Minimal thermal changes were elicited with LED lamps at the level of the dentin, in comparison to the halogen curing light in all three types of materials used. In addition, the thermal behavior of the dual-cured restorative resin was influenced by the resin shade and active polymerization phase of the material. In regard to maintaining the health of the tooth structure, mainly pulp, LED-based curing lights were safer. The maximum rise in temperature as a result of irradiation with these curing lights to the teeth was $2.36^{\circ}$ well below the threshold for pulpal injury.

An additional point raised by the study was in a deeply prepared cavity in a tooth with a smaller amount of residual dentin of $1 \mathrm{~mm}$ the potential for pulp damage was greater as the flow of heat through dentin was proportional to the thermal conductivity of the material and the curing light source used. Among the materials, the flowable bulk-fill composite used, which can be placed to a thickness of about $4 \mathrm{~mm}$ may be beneficial to decrease the thermal insult to the underlying structures of the dentin along with composite material.

\section{Conclusion}

The difference in the temperature rise relates to the differences in the light intensity output along with the composition of the resin matrix, the filler content, and the shade of the materials being used. Being familiar with the temperature changes that have been observed in the present study, halogen curing device and dualcured Cention $\mathrm{N}$ material had produced the striking difference in the amount of heat produced. The rise in exothermic temperature was not in significance to cause irreversible changes to the underlying structures below the dentin during the process of polymerization with the curing devices.

\section{References}

1. Mangat $P$, Dhingra A, Bhardwaj G. Curing lights and the science behind them - an overview. IOSR-JDMS [Internet] 2014;13(12):35-39. DOI: 10.9790/0853-131243539Available from: https://www.scribd. com/document/ 250717030/Curing-Lights-and-the-science-behindthem-An-Overview.

2. Jung $\mathrm{H}$, Friedl $\mathrm{KH}$, Hiller KA, et al. Polymerization efficiency of different photocuring units through ceramic discs. Oper Dent 2006;31(1):68-77. DOI: $10.2341 / 04-188$.

3. Price RB, Ferracane $\mathrm{J}$, Shortall AC. Light-curing units: a review of what we need to know. J Dent Res 2015;94(9):1179-1186. DOI: $10.1177 / 0022034515594786$

4. Ilday NO, Sagsoz O, Karatas O, et al. Temperature changes caused by light curing of fiber-reinforced composite resins. J Conserv Dent 2015;18(3):223-226. DOI: 10.4103/0972-0707.157258.

5. Mouhat M, Mercer J, Stangvaltaite L, et al. Light-curing units used in dentistry: factors associated with heat development-potential risk for patients. Clin Oral Investig 2017;21(5):1687-1696. DOI: 10.1007/ s00784-016-1962-5.

6. Peutzfeldt A, Lussi A, Flury S. Effect of high-irradiance light-curing on micromechanical properties of resin cements. Biomed Res Int 2016;2016:4894653. DOI: $10.1155 / 2016 / 4894653$.

7. Lopez JV, Gomez MAC, Oronia MAR, et al. Analysis and simulation of heat transfer in human tooth during the curing of orthodontic appliance and food ingestion. APOS Trends Orthodont [Internet] 2016;6(3):137-146. DOI: 10.4103/2321-1407.183153Available from http://www.apospublications.com/downloadpdf.asp?issn=23211407; year $=2016$; volume $=6$;issue $=3$; ppage $=137$; epage $=146$; aulast $=$ Velazquez-Lopez;type $=2$.

8. Yu C, Abbott PV. An overview of the dental pulp: its functions and responses to injury. Aust Dent J 2007;52(1 Suppl):S4-S16. DOI: 10.1111/j.1834-7819.2007.tb00525.x.

9. Armellin E, Bovesecchi G, Coppa P, et al. LED curing lights and temperature changes in different tooth sites. Biomed Res Int 2016;2016:1894672. DOI: 10.1155/2016/1894672.

10. Uzel A, Buyukyilmaz T, Kayalioglu $M$, et al. Temperature rise during orthodontic bonding with various light-curing units--an in vitro study. Angle Orthod 2006;76(2):330-334. 
11. Xu HH. Dental composite resins containing silica-fused ceramic single-crystalline whiskers with various filler levels. J Dent Res 1999;78(7):1304-1311. DOI: 10.1177/00220345990780070401.

12. Matthews $B$, Andrew D. Microvascular architecture and exchange in teeth. Microcirculation 1995;2(4):305-313. DOI: 10.3109/10739689509148275.

13. Zach L, Cohen G. Pulp response to externally applied heat. Oral Surg Oral Med Oral Pathol 1965;19(4):515-530. DOI: 10.1016/00304220(65)90015-0.

14. Knezevic A, Tarle Z, Meniga A, et al. Degree of conversion and temperature measurement of composite polymerized with halogen and LED-curing unit. Actastomatolog Croat [Internet] 2003;37(2): 165-168. Available from: https://hrcak.srce.hr/file/4257.

15. Raab WH. Temperature related changes in pulpal microcirculation. Proc Finn Dent Soc 1992;88(Suppl 1):469-479.

16. Hervas-Garcia A, Martinez-Lozano MA, Cabanes-Vila J, et al. Composite resins. A review of the materials and clinical indications. Med Oral Patol Oral Cir Bucal 2006;11(2):E215-E220.

17. Knezevic A, Tarle Z, Meniga A, et al. Photopolymerization of composite resins with plasma light. J Oral Rehabil 2002;29(8):782-786. DOI: 10.1046/j.1365-2842.2002.00897.x.

18. Oliveira M, Cesar PF, Giannini M, et al. Effect of temperature on the degree of conversion and working time of dual-cured resin cements exposed to different curing conditions. Oper Dent 2012;37(4):370-379. DOI: 10.2341/11-198-L.

19. Pilo R, Oelgiesser D, Cardash HS. A survey of output intensity and potential for depth of cure among light-curing units in clinical use. J Dent 1999;27(3):235-241. DOI: 10.1016/S0300-5712(98) 00052-9.
20. Berzins DW, Abey $S$, Costache $M C$, et al. Resin-modified glass-ionomer setting reaction competition. J Dent Res 2010;89(1):82-86. DOI: 10.1177/0022034509355919.

21. Kahvecioglu F, Tosun G, Ulker HE. Intrapulpal thermal changes during setting reaction of glass Carbomer ${ }^{\oplus}$ using Thermocure lamp. Biomed Res Int 2016;2016:5173805. DOI: 10.1155/2016/5173805.

22. Mousavinasab SM, Salehi A, Salehi N. Effect of composite shade, curing time and mode on temperature rise of silorane and methacrylate-based composite resins. Caspian J Dent Res [Internet] 2016;5(2):50-58. Available from: https://cjdr.ir/article-1-185-en.pdf.

23. Emami N, Sjodahl M, Soderholm KJ. How filler properties, filler fraction, sample thickness and light source affect light attenuation in particulate filled resin composites. Dent Mat 2005;21(8):721-730. DOI: 10.1016/j.dental.2005.01.002.

24. Vita Zahnfabrik H, Rauter GmbH \& Co [Internet]. Germany: DENTSPLY DeTrey $\mathrm{GmbH}_{\text {; }}$ Spectrum ${ }^{\oplus}{ }^{\text {TPH }}{ }^{\oplus}$ : [cited 2017 Nov]; [about 7 p.]. Available from: http://www.dentatechnica.com/language/bg/ uploads/files/dentalmed__2/dentalmed__2__2970d8a6e5bf9c6b 991d0c7b1729b98f.pdf.

25. Karatas $\mathrm{O}$, Turel $\mathrm{V}, \mathrm{Bayindir} Y \mathrm{Z}$. Temperature rise during polymerization of different cavity liners and composite resins. J Conserv Dent 2015;18(6):431-435. DOI: 10.4103/0972-0707.168795.

26. Souza-Junior EJ, Prieto LT, Soares GP, et al. The effect of curing light and chemical catalyst on the degree of conversion of two dual cured resin luting cements. Lasers Med Sci 2012;27(1):145-151. DOI: 10.1007/ s10103-010-0857-y.

27. Zimmerli B, Strub M, Jeger F, et al. Composite materials: composition, properties and clinical applications. A literature review. Schweiz Monatsschr Zahnmed 2010;120(11):972-986. 